\title{
Asbestos management: Duty holders' responsibilities under the new regulations and a typical methodology for a survey
}

Received (in revised form): 15th April, 2005

\section{David Mann BSc (Hons), MRICS}

is a chartered building surveyor and partner at Tuffin Ferraby Taylor LLP, based at their London office and specialising in building surveying consultancy to the commercial sector. He has particular experience in due diligence and has developed a specialism in asbestos surveys and consultancy. He is also a member of the RICS Working Party that has recently produced the 3rd edition of the Guidance Note on Building Surveys and Inspections of Commercial and Industrial Property.

\begin{abstract}
Over the past 12 months there has been a glut of articles within all manner of technical and more general press heralding the introduction of the latest amendments to the Control of Asbestos at Work Regulations 2002 (CAWR). These generally have been sirens of doom quoting alarming Health \& Safety Executive (HSE) statistics for anticipated asbestos-related deaths while outlining the new duties introduced by Regulation 4 of the CAWR, all in an attempt to reduce the risks associated with working in a building containing asbestos. The Health \& Safety at Work Act 1974 and Construction (Design \& Management) Regulations 1994 having been found to be sadly lacking in this respect in the past. The aim of this paper is to provide some practical advice to assist duty holders and their advisers to comply with their responsibilities as well as outlining a typical methodology for an asbestos survey.
\end{abstract}

\section{Keywords:}

asbestos, duty holder, asbestos survey, asbestos surveyor, asbestos management plan

\section{INTRODUCTION}

Since 21st May, 2004, Regulation 4 of the Control of Asbestos at Work Regulations 2002 (CAWR) came into force. This Regulation imposes a new duty on occupiers and owners of non-domestic properties to record and manage asbestos. The 'duty holder' is defined as anyone, by virtue of a contract or tenancy, having an obligation for the maintenance and/or repair of non-domestic premises. If there is no contract or lease, the duty holder is anyone in physical control of premises, access or egress thereto, ie potentially building owners, landlords, tenants, sub-tenants, facilities managers, managing agents, contractors, surveyors, architects and employers. There may be more than one duty holder, for example, within a multi-tenanted office building. The duty also applies to common parts of 


\section{What are our duties?}

\section{Difficult to give generic advice}

\section{Information sharing}

premises, including housing developments and blocks of flats but currently does not place any direct duty on landlords in respect of individual houses or flats.

The duties under the new regulations can be summarised as follows:

- Take reasonable steps to determine the location and condition of materials likely to contain asbestos.

- Presume materials contain asbestos unless there is strong evidence that they do not.

- Make and keep an up-to-date record of the location and condition of asbestos containing materials (ACMs) or presumed ACMs in the premises.

- Assess the risk of the likelihood of anyone being exposed to fibres from these materials.

- Prepare a plan setting out how the risks from the materials are to be managed.

- Take the necessary steps to put the plan into action.

- Review and monitor the plan periodically.

- Provide information on the location and condition of the materials to anyone who is liable to work with or disturb them.

The Health and Safety Executive (HSE) has been keen to point out that the new regulations do not impose a 'duty to survey'. They have been highly critical of some organisations misselling expensive asbestos surveys. The regulations largely are aimed at raising awareness of asbestos and preventing it being accidentally disturbed by maintenance workers, electricians, alarm installers, surveyors and the like. Notwithstanding this, it can be difficult to see how the new duties can be discharged without a specialist survey, particularly in 'high risk' buildings.

It can be problematic giving generic advice about an asbestos strategy as it will depend considerably upon the nature of the client organisation, ie commercial landlord or housing association, as well as the number, size and age profile of the subject building or portfolio of buildings.

\section{WHAT PRACTICAL STEPS SHOULD BE TAKEN IN AN ATTEMPT TO COMPLY WITH THESE REGULATIONS?}

\section{Step 1: Do a desktop study of available plans and specifications} Contact others such as the landlord, tenant, building manager/caretaker, architect or contractor to ascertain all the existing knowledge they have. Regulation 4 includes a duty to share information between all parties and this may include organisations such as the emergency services responding to an incident within a building, an internal or external contractor about to undertake works within a property or a surveyor undertaking a building inspection. Increasingly, organisations need to induct employees and visitors to their building. Traditionally, this just meant pointing out the fire exits but this should now include a review of the asbestos register and/or asbestos management plan. 


\section{Assess risk and prioritise}

\section{Asbestos awareness training}

It is reasonable to assume that all commercial buildings built prior to 1975 contain some ACMs. This equates to around 75 per cent of commercial buildings in the UK. ${ }^{1}$ In total, about six million tonnes of asbestos, mainly chrysotile (white), have been imported into the UK since the turn of the century. The sale of asbestos products increased considerably after the Second World War and imports peaked in the 1960s and 1970s. The importation, use in manufacturing and marketing of amosite (brown) and crocidolite (blue) - the two most dangerous forms of asbestos - have been prohibited in the UK since 1986 under the Asbestos (Prohibitions) Regulations. Chrysotile (white) asbestos has been banned since 1999 .

The use of such data should allow someone at least to rate their buildings into relative risk categories and prioritise them according to their likelihood of containing ACMs and which types of asbestos may be present.

\section{Step 2: Carry out an inspection of the building(s)}

An initial, in-house inspection may be adequate providing it is recorded and any suspect materials are assumed to contain asbestos until proven otherwise. The person undertaking the inspection needs to be competent and asbestos awareness training is readily available at relatively low cost. It is also possible to obtain guidance upon individual building products, including their anticipated asbestos content and the approximate date of manufacture utilising asbestos.

There are over 3,000 different known uses of asbestos and others are still being encountered, the following are just a few examples.

\section{Sprayed coatings}

Thermal, acoustic and fire insulation containing up to 85 per cent asbestos and utilising a mixture of asbestos types were used up until 1974. Such sprayed coatings were often used to insulate a steel structural frame.

\section{Insulating boards}

Insulating boards used for fire protection, thermal and acoustic insulation and general building work (trade names 'Asbestolux' and 'Marinite') containing 16-40 per cent amosite or a mixture of amosite and chrysotile ceased manufacture in the UK in 1980 and are unlikely to be found in buildings constructed after 1982. Crocidolite was used for some insulating boards up to 1965 .

\section{Asbestos cement products}

Asbestos cement products were widely used as profiled or flat cladding to walls and roofs, tiles and slates, and preformed moulded products, ie water tanks, rainwater goods and window boxes, with an asbestos content of $10-15$ per cent bound in with Portland cement. All three types have been used, crocidolite between 1950 and 1969, amosite from 1945 to at least 1976, but mainly chrysotile up until 1999. 
Complex or high risk buildings warrant a specialist survey

\section{Flooring materials}

Asbestos containing thermoplastic floor tiles (25 per cent asbestos), PVC floor tiles (less than 10 per cent chrysotile) and asbestos paper-backed PVC tiling (paper backing approximately 100 per cent chrysotile) were used until manufacture generally ceased around 1984.

\section{Textured coatings}

Asbestos containing coatings to walls and ceilings, ie Artex (3-5 per cent chrysotile), were used until supply and application ceased in 1988 but much is still in place.

\section{Step 3: Survey planning}

More complex buildings or those categorised as being of higher risk following the initial in-house inspection may warrant a specialist asbestos survey. This survey should be undertaken in accordance with the HSE's publication: Methods for the Determination of Hazardous Substances 100: Surveying, Sampling and Assessment of Asbestos Containing Materials (MDHS 100). ${ }^{2}$ Anyone commissioning a particularly complex or large number of asbestos surveys would be well-advised to read this document as it provides guidance upon who should be appointed to undertake the survey, the different types of survey available, survey methodology and information that should be recorded.

Generally, a suitably qualified and independent asbestos surveyor holding a minimum of the Proficiency Certificate P402: Building Surveys and Bulk Sampling for Asbestos issued by the British Occupational Hygienists Society (BOHS) should be commissioned (Figure 1). There are also a number of accreditation schemes, such as those administered by the United Kingdom Accreditation Service (UKAS) and the National Individual Asbestos Certification Scheme (NIACS), a joint venture by the Royal Institution of Chartered Surveyors (RICS) and Asbestos Removal Contractors Association (ARCA).

As a general rule, free surveys should be avoided, particularly if offered by an asbestos removal contractor. The advice received may result in very costly and often unnecessary asbestos removal works.

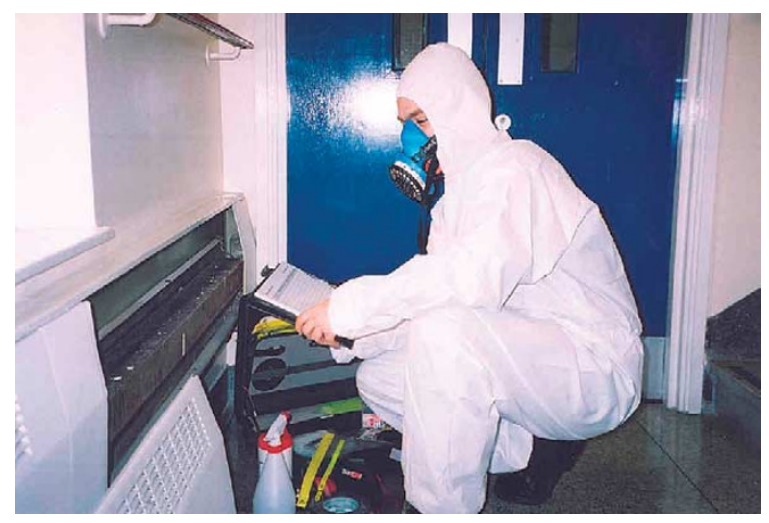

Figure 1: Use a suitably qualified and independent asbestos surveyor 


\section{Types of asbestos survey available}

The objective of a survey is to determine, as far as is reasonably practicable, the presence of ACMs and suspected ACMs within the building/premises. Any ACMs identified throughout the course of the survey can then be monitored and subsequently managed. The following types of survey are available:

\section{Type 1}

This location and assessment (presumptive) survey is purely visual, identifying materials likely to contain asbestos. All materials that are presumed to contain asbestos are identified and recorded in an asbestos register. Due to the unobtrusive nature of this type of survey, this register may contain non-ACMs which will have to be managed by the duty holder as if they are ACMs.

\section{Type 2}

This is an extended Type 1, standard sampling, identification and assessment (sampling) survey, with suspect ACMs being sampled and analysed. This type of survey is intrusive and surveyors will take samples, where possible, from accessible areas. Should it be necessary to take a sample from a visible area the surveyor will attempt to make good to a standard already pre-agreed with the client. This level of survey provides the duty holder with an asbestos register of known ACMs, consequently there is a saving on management over Type 1. This level of survey will not identify hidden ACMs that may be located within the building structure, cavities etc.

\section{Type 3}

This full access, sampling and identification (pre-demolition/major refurbishment) survey is used to locate and describe, as far as is reasonably practicable, all ACMs in the building and may involve destructive inspection. It is often used to identify and quantify ACMs as a basis for tendering their removal before demolition or major works. This survey should address the following elements:

- It must, as far as reasonably practicable, locate and record the location, extent and product type of any presumed or known ACMs.

- It must assess and record information on the accessibility, condition and surface treatment of any presumed or known ACMs.

- It must determine and record the asbestos type, either by collecting representative samples of suspect materials for laboratory identification, or by making a presumption upon the product type and its appearance.

- The survey will include examining above false ceilings, inside risers, service ducts, lift shafts etc, where safe access can be obtained without the need for specialist access equipment. Attendance by the client's lift or services engineer may be required to access lift shafts and plant rooms. For health and safety reasons, for footing ladders, working within confined spaces, empty properties etc, the sampling process should be a two-person operation. 
- Where access is not available due to circumstances outside the surveyor's control or due to health and safety reasons, that room/area will be marked within the report as 'unsurveyed due to no access' and, in accordance with MDHS 100, will be presumed to contain asbestos until proven otherwise.

- In sensitive or occupied buildings, it may be necessary to undertake a Type 1, location and assessment ('walk-through') survey during normal working hours to identify all suspect ACMs for subsequent sampling outside normal working hours. Each property/site will have to be assessed at commencement of the inspection.

\section{A report should include}

Criteria to be included within a report, as a minimum, are as follows.

- Site location

- Building location

- Precise location within room/area/element

- Date of investigation

- Sample reference/identity

- Related colour photographs, with sample references where applicable

- Description of material (product type)

- Form (type of asbestos)

- Condition

- Recommendation of appropriate action(s) to be taken

- Plan showing locations and extent of affected areas

- Full risk assessment with recommendations and priorities for future management.

\section{Step 4: Asbestos management plan}

ACMs in good condition are often better left in situ
The HSE advocates that, if ACMs are in good condition and are unlikely to be disturbed by everyday use, then they are better left in place subject to their repair and encapsulation, if required. Indeed, it is illegal to expose workers unnecessarily to asbestos fibres so all removal needs to be considered carefully and justified. In addition, the number of licensed refuse tips is rapidly reducing with the resultant increasing cost of disposal. Risks to human health, environmental impact and capital cost need to be balanced.

A 'label and manage' regime may be put in place with all ACMs being recorded within an asbestos register and management plan. This is where the most important duty under the new regulations applies: 'The Duty to Manage'. Again, in most instances this can be undertaken in-house with limited training.

\section{Direct management actions}

- Label: needs to be clear and durable, conforming to Health \& Safety (Safety, Signs \& Signals) Regulations 1996 (see Figure 2) (nonasbestos materials can also be labelled where confusion may occur) 


\section{Regularly review asbestos management}

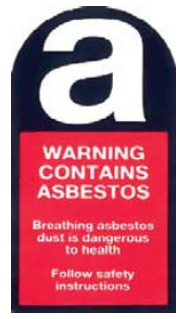

Figure 2: Example of clear labelling

- Decontaminate

- Repair

- Enclose/protect

- Encapsulate/paint

- Remove.

\section{Indirect management actions}

- Warning: verbal/written

- Monitor condition

- Isolate: seal off (permanent/temporary)

- Restrict access: permit to access

- Restrict work: permit to work

- Training: induction and 'toolbox' talks

- Site rules: contractor rules.

All asbestos records, procedures, training and safe systems of working should be monitored and reviewed regularly. The purpose of this ongoing monitoring is to ensure that the aims of the asbestos management strategy are being met and that no one is being exposed to asbestos fibres by accidentally working upon it or the material becoming damaged by the building's normal occupation.

Asbestos documentation should be collated and kept in a central, controlled location and a person or persons nominated as the Asbestos Coordinator, often in tandem with other health and safety responsibilities.

The retention of the asbestos register on a computer database and management system can assist this process, especially for a large portfolio of properties or complex building, such as a shopping centre. Such a system can be made accessible via an intranet to improve the sharing of this information. Many proprietary systems are available; however, many are over-complicated and the author has yet to find one that he is completely happy to recommend unreservedly.

The management plan may include items such as the following.

- Asbestos survey report

- Records of reinspections/monitoring

- Details of remedial or removal work

- Emergency procedures 


\section{Maintenance works - known and unknown ACMs}

- Areas of no or restricted access

- List of approved (asbestos) contractors

- Records of exposure/incidents

- Training records/site inductions.

The management plan also should include procedures for routine maintenance with safe systems of working to deal with day-to-day maintenance, reactive maintenance and minor works. By their nature, reactive works are not planned; however, procedures need to be put in place to avoid any risk of disturbing a known ACM. This may require simply making reference to the asbestos register relevant to the location of the works prior to commencement. Notwithstanding this, operatives also need to be equipped with sufficient knowledge to identify potential ACMs to prevent them working on unknown ACMs not recorded in the register.

Planned maintenance works are usually easier to deal with as they permit time for a risk assessment to be undertaken. Major works generally come under the jurisdiction of the Construction (Design and Management) Regulations 1994 and such risks are usually identified within the pretender or construction phase 'Health and Safety Plan', often following a targeted Type 3 asbestos survey within the area of works. This situation allows the planning of works on or near ACMs. Risks can be designed out and may require the involvement of a licensed contractor and notification to the HSE with a task-specific method statement being generated.

\section{Step 5: Land remediation tax relief?}

In simple terms, this is an additional tax relief or credit available to any company that remediates contaminated land or buildings that have been acquired in a contaminated state, ie the party undertaking the works was not the original contaminator. This stage can include the encapsulation, treatment or removal of a wide variety of contaminants including asbestos, hydrocarbons, heavy metals, acids and chemicals.

The benefit is realised either as tax relief, which effectively saves up to 45 per cent of the cost incurred, or as a tax credit resulting in a cash payment from the Inland Revenue equivalent to 24 per cent of the cost. With the significant sums often associated with asbestos removal, this can have a significant effect upon the viability of a refurbishment or redevelopment project. However, this tax relief, introduced by the Office of the Deputy Prime Minister in the 2001 budget, appears to encourage the removal of asbestos contradicting the advice issued by the HSE, which advocates the retention and management of ACMs in situ.

\section{CONCLUSION}

On the face of it, Regulation 4 is just another duty on an already overburdened property industry. Experience shows, however, that all too often during some of the asbestos surveys recently completed, there are instances where ACMs are in a poor condition and are an immediate risk to human health. Anything that reduces the risk and saves lives in the long term has to be justified.

\section{Anthing that saves lives has to be justified!}




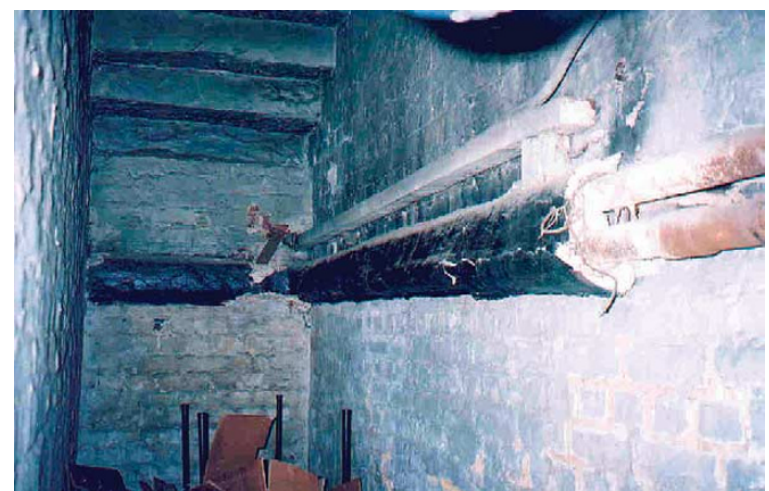

Figure 3: Pipe lagging in the boiler house of a private school

For example, Figure 3 shows a section of pipe lagging in the boiler house of a private school. It was a Type 2 survey and the sample analysed indicated that it contained both blue and brown asbestos. It was clearly in a poor condition with loose and missing sections and the entire room was found to be contaminated with asbestos fibres. The area was accessed regularly and the boilers had been replaced within the last two years. Maintenance workers and contractors had been exposed. What was in some way even worse was that examination desks were being stored directly below the pipes (see Figure 3). The desks were also contaminated and it was reasonable to assume that some students potentially had been exposed to some fibres.

While unlikely to be immediately life-threatening, any exposure should be kept to an absolute minimum because of the cumulative nature of asbestos-related diseases like asbestosis and mesothelioma, where several small exposures are as bad as exposure to a high concentration of airborne fibres.

The final word on this subject is to act now if anyone has not already done so. The HSE and local Environmental Health Officers are tasked with enforcing these regulations and may be knocking on doors and asking to see an asbestos management plan. Worse still, they may be requesting it as part of an investigation into an accidental release of asbestos fibres and exposure of an employee.

\section{References}

DETR (1999) Asbestos and Manmade Mineral Fibres in Buildings — Practical Guidance, DETR, Thomas Telford, London, UK.

Health \& Safety Executive (HSE) (2001) Methods for the Determination of Hazardous Substances 100: Surveying, Sampling and Assessment of Asbestos Containing Materials, HSE, Available at: www.hse.gov.uk/pubns/mdhs/pdfs/mdhs100.pdf

HMSO (2004) Control of Asbestos at Work Regulations, available at: www. legislation.hmso.gov.uk/ si/si2002/20022675.htm. 